\title{
Formulation, Characterization and In Vitro Skin Penetration of Green tea (Camellia sinensis L.) Leaves Extract-Loaded Solid Lipid Nanoparticles
}

\author{
Selvina Dzulhi ${ }^{1}$, Effionora Anwar ${ }^{2 *}$, Tati Nurhayati ${ }^{3}$ \\ ${ }^{1}$ National Agency of Drug and Food Control of Republic of Indonesia, Central Jakarta 10560, Special Capital Region of Jakarta, Indonesia. \\ ${ }^{2}$ Department of Pharmaceutical Technology, Faculty of Pharmacy, Universitas Indonesia, Depok 16424 West Java, Indonesia. \\ ${ }^{3}$ Department of Aquatic Products Technology, Faculty of Fisheries and Marine Sciences, Bogor Agricultural University, Bogor 16680 West Java, Indonesia.
}

\section{ARTICLE INFO \\ Article history: \\ Received on: 05/12/2017 \\ Accepted on: 27/06/2018 \\ Available online: $31 / 08 / 2018$}

Key words:

solid lipid nanoparticle

(SLN), Camellia sinensis,

skin penetration, solvent

emulsification, green tea,

epigallocatechin gallate

(EGCG).

\begin{abstract}
Purpose: This study aims to formulate and evaluate the characteristics and the skin penetration of green tea leaves extract loaded solid lipid nanoparticles (GT-SLN). Methods: GT-SLN was prepared by solvent emulsificationevaporation method. The properties of SLN were characterized by dynamic light scattering (DLS), transmission electron microscopy (TEM), differential scanning calorimetry (DSC), and in vitro penetration studies were investigated with Franz diffusion cells. Results: The GT-SLN1 presented spherical shape with an average particle size of 155.6 $\pm 10.04 \mathrm{~nm}$; polydispersity index of $0.409 \pm 0.05$; zeta potential of $-30.967 \pm 1.29$; entrapment efficiency of 81.124 $\pm 0.443 \%$. In vitro penetration study with Franz diffusion cell showed flux value from GT-SLN1 of $1.965 \pm 0.025$ $\mu \mathrm{g} / \mathrm{cm}^{2}$.hour and GT $0.261 \pm 0.005 \mu \mathrm{g} / \mathrm{cm}^{2}$.hour. Conclusion: In vitro skin penetration study showed that solid lipid nanoparticles improved the penetration of epigallocatechin gallate (EGCG) through the stratum corneum.
\end{abstract}

\section{INTRODUCTION}

Green tea has become a popular drink and often consumes widely in Indonesia. Green tea is produced by drying young fresh leaves from Camellia sinensis L. plant. The green tea leaves extract has a major component of polyphenols. Polyphenols are known to have even higher potent antioxidant activity compared with vitamin E and vitamin C (Jigisha et al., 2012). Green tea leaves extract also has the ability to inhibit the tyrosinase enzyme (Gillbro et al., 2011). Polyphenols from green tea potent as free radical binders due to hydroxyl groups in their chemical structure. The main flavonoids in green tea are catechins, with a content of $25-35 \%$ of the dry weight of green tea leaves (Aafrin, 2013).

\footnotetext{
${ }^{*}$ Corresponding Author

Effionora Anwar, Department of Pharmaceutical Technology, Faculty of Pharmacy, Universitas Indonesia, Depok 16424 West Java, Indonesia. E-mail:effionora.anwar@farmasi.ui.ac.id
}

The four catechin compounds found in green tea are epicatechin, epicatechin gallate, epigallocatechin, and epigallocatechin gallate. Epigallocatechin gallate is the largest compound of all, about 59\% of total catechins (Sinija and Mishra, 2008; Krishnaveni, 2012).

Epigallocatechin gallate must be able to penetrate into the skin in order to provide optimal antioxidant and tyrosinase activity. Epigallocatechin gallate has a hydrophilic property with a water solubility of $521.7 \mathrm{~g} / \mathrm{L}$, partition coefficient (Log P) of 0.48 (Patel and Velikov, 2013), molecular weight 458.37, and unstable at a high temperature $\left(>50^{\circ} \mathrm{C}\right)$, and alkaline $\mathrm{pH}(\mathrm{pH}>8)$ (Namal, 2013). Some research studies suggest that catechins have low penetration ability due to its hydrophilic properties and also because of chemical interactions with skin lipid bilayer (Scalia et al., 2014; Sun et al., 2009). Therefore, an effort is needed to overcome the problem, one of it is using the carrier system in such as solid lipid nanoparticles.

Solid lipid nanoparticles (SLN) is colloidal 
nanoparticulate system which is composed of biocompatible and biodegradable materials in the nanometer size range with an average particle size of 40-1000 nm (Müller et al., 2002; Balguri et al., 2016). SLN is made of solid lipid with a concentration of $0.1-30 \%(\mathrm{w} / \mathrm{w})$, surfactant with a concentration of $0.5-5 \%(\mathrm{w} / \mathrm{w})$, and water (Pardeike et al., 2009). The quality of SLN dispersion is influenced by the selection of ingredients and the concentration of lipids and surfactants as emulsifiers (Mehnert and Mader, 2012). The advantages of SLN in cosmetic preparations are high occlusion properties that can increase the penetration of active substances through the stratum corneum on the skin, able to improve the stability of the active compounds by protecting from degradation and increase skin hydration so that able to enhance skin penetration.

In this study, green tea leaves extract was made in SLN dosage form using solvent emulsification-evaporation method. Green tea leaves extract SLN was prepared with variations of concentration of solid lipids and performed SLN characterization obtained. In order to see the impact of creating SLN for green tea leaves extract, penetration test was çonducted on female rats skin using Franz diffusion cell.

\section{MATERIALS AND METHOD}

\section{Materials}

Green tea (Camellia sinensis L.) leaves extract was purchased from Andy Biotech (Xi'an Co Ltd, Cina), epigallocatechin gallate standard (Sigma-Aldrich), glyceryl monostearate $\left(\right.$ Cutina ${ }^{\circledR}$, was kindly provided by BASF), lecithin (phospholipon $\AA$ 90G, Lipoid), poloxamer 188 (Pluracare $\mathbb{}$ F68 G, was kindly provided by BASF), potassium dihydrogen phosphate (Merck), sodium hydroxide pellets for analysis (Merck), ethanol absolute for analysis (Merck), dichloromethane (Merck), demineralized water (Brataco), and Female SpragueDawley rats aged 2-3 months with average weight 200 grams (Bogor Agricultural University, Indonesia).

\section{Preparation of GT-SLN}

SLN was prepared by modified solvent emulsificationevaporation method referring to Kelidari et al. (2015). Green tea leaves extract powder was dissolved in $3 \mathrm{~mL}$ ethanol, then glyceryl monostearate (GMS) and lecithin were dissolved in 10 $\mathrm{mL}$ dichloromethane (DCM). Both solutions were mixed using a homogenizer (Edmund Buhler D-7400 Tubingen) at 30,000 rpm for 15 minutes. Poloxamer 188 was added to the mixture then homogenized at $30,000 \mathrm{rpm}$ for 15 minutes. The SLN forming process was continued by evaporating the organic solvent (DCM) with a magnetic stirrer $(3,000 \mathrm{rpm})$ for 3 hours under a fume hood at room temperature.

\section{Particle characterization}

Particle size and polydispersity index (PDI) of SLN was determined by Particle Size Analyzer (PSA) with dynamic light scattering (DLS) method. DLS measurements were performed at $90^{\circ}$ light scattering and temperatures of $25^{\circ} \mathrm{C} \pm 0.1^{\circ} \mathrm{C}$. Suspension of SLN was diluted in demineralized water and filtered using a $0.2 \mu \mathrm{m}$ filter membrane. Particle size, PDI and zeta potential (ZP) were measured using a Zeta Sizer Nano-ZS (Malvern Instruments, Malvern, UK).

\section{Transmission electron microscopy (TEM)}

Morphology and form of SLN were observed with a transmission electron microscope (TEM). Samples were added with $2 \%$ phosphotungstic acid and placed on a copper grid to be observed using TEM.

\section{Differential scanning calorimetry (DSC)}

DSC was used to determine the thermal properties. Samples were packaged in aluminum under nitrogen, with a heating rate of $10^{\circ} \mathrm{C} / \mathrm{min}$ and evaluated at 20 to $200^{\circ} \mathrm{C}$ temperature intervals. DSC analysis was performed on green tea leaves extract powder, GMS powder, a physical mixture of green tea leaves extract-GMS, and GT-SLN with DSC (DSC60, Shimadzu, Japan).

\section{Entrapment efficiency}

The entrapment efficiency of SLN suspension was determined by the centrifugation method based on Kelidari et al. (2015) with modification. The SLN suspension was inserted into a centrifugation tube, then the sample is centrifuged at 9,000 rpm for 1.5 hours. The supernatant was then diluted with mobile phase, consisted of acetic acid $(0.05 \%, v / v)$ : acetonitrile $(87: 13$, $\mathrm{v} / \mathrm{v})$, then filtered with $0.45 \mu \mathrm{m}$ filter membrane and then analyzed using HPLC Shimadzu LC-20AD with the C-18 column (Waters, XBridge $\left({ }^{\circledR}\right)$, flow rate of $1.0 \mathrm{~mL} / \mathrm{min}$ and detected at $280 \mathrm{~nm}$ through a UV detector. The injection volume was $20 \mu \mathrm{L}$ and a total running time of $12 \mathrm{~min}$ with the column temperature at $25^{\circ} \mathrm{C}$. Peak area was measured as the value of free EGCG. Entrapment efficiency $(\% \mathrm{EE})$ is determined using the following Eq. (1):

$$
\% \mathrm{EE}=\left(\left(\mathrm{W}_{\mathrm{i}}-\mathrm{W}_{\mathrm{f}}\right) / \mathrm{W}_{\mathrm{i}}\right) \times 100 \%,
$$

where $\mathrm{W}_{\mathrm{i}}$ is the total amount of drug added in the formulation and $\mathrm{W}_{\mathrm{f}}$ is the amount of free drug in the supernatant.

\section{In vitro skin penetration study}

Skin penetration test by Franz diffusion cells method has been approved by the Ethics Committee of the Faculty of Medicine, Universitas Indonesia with approval number 390/UN2. F1/ETIK/2017. In order to perform in vitro skin penetration study, each GT-SLN and GT was made into a cream dosage form. The membrane used in this study was the abdominal skin of Sprague Dawley female rats, aged 2-3 months with an average weight of $200 \mathrm{~g}$. Ether was used to anesthetic the Rat. The abdominal part was shaved carefully, and the abdominal skin is slashed and the subcutaneous fat removed thoroughly. The abdominal skin then was immersed in phosphate buffer $\mathrm{pH} 5.5$ for $30 \mathrm{~min}$ before storing at $4^{\circ} \mathrm{C}$. The skin can be used within 24 hours.

In vitro penetration study was performed using Franz diffusion cells with membrane area $1.76 \mathrm{~cm}^{2}$. The receptor compartment was filled with a $15 \mathrm{~mL}$ of phosphate buffer ( $\mathrm{pH}$ 5.5) and maintained at $37 \pm 1{ }^{\circ} \mathrm{C}$ and stirred with a magnetic stirrer at $300 \mathrm{rpm}$. The skin was placed between the donor compartment and the receptor compartment with the stratum corneum position facing upward. Approximately $1 \mathrm{~g}$ of sample was applied to the skin surface. Then, at 1, 2, 3, 4, 5, 6, 7, 8, 9, 10, 11 and $12 \mathrm{~h}$, samples were taken $3.0 \mathrm{~mL}$ from receptor compartment using a syringe and immediately replaced with phosphate buffer $\mathrm{pH} 5.5$ with the similar volume. Each sample was taken from triplicates. Samples were analyzed with HPLC as described before. 
The cumulative amount $(\mathrm{Q})$ of samples penetrated per diffusion area $\left(\mu \mathrm{g} / \mathrm{cm}^{2}\right)$ was calculated by Eq. (2) (Thakker and Chern, 2003):

$$
Q=\left(C n . V+\sum_{i=1}^{n-1} C \cdot S\right) / A
$$

$\mathrm{Q}=$ cumulative amount of EGCG penetrated per area of diffusion $\left(\mu \mathrm{g} / \mathrm{cm}^{2}\right) . \mathrm{Cn}=$ concentration of EGCG $(\mu \mathrm{g} / \mathrm{ml})$ on the $n$th sampling interval. $\mathrm{V}=$ volume of Franz diffusion cell. $\quad \sum_{i=n}^{n-1} \mathrm{C}=$ the amount of EGCG $(\mu \mathrm{g} / \mathrm{ml})$ concentration in the first sampling until before the $\mathrm{n}$ th minute. $\mathrm{S}=$ sample volume $(\mu \mathrm{L}) . \mathrm{A}=$ area of membrane $\left(\mathrm{cm}^{2}\right)$. For this research, the area of the membrane was $1.76 \mathrm{~cm}^{2}$.

The calculation of flux $(\mathrm{J})$ of drug was performed using equations based on Fick I law: $J=M /(S \times t)$. Where: $J$ is the flux $\left(\mu \mathrm{g} . \mathrm{cm}^{-2}\right.$.hour $\left.{ }^{-1}\right), \mathrm{M}$ is the cumulative amount of EGCG through the membrane $(\mu \mathrm{g}), \mathrm{S}$ is the area of diffusion $\left(\mathrm{cm}^{2}\right)$ and $\mathrm{t}$ is time (hours). Furthermore, a graph of the cumulative amount of EGCG penetrated $(\mu \mathrm{g})$ per area of diffusion $\left(\mathrm{cm}^{2}\right)$ was made with time (hours). The slope of this curve was the flux value.

\section{RESULTS AND DISCUSSION}

\section{SLN preparation and characterization}

The chosen method for SLN preparation was solvent emulsification-evaporation (Mehnert and Mader, 2012). The advantages of such method are do not require heating, easy to use in avoiding the active ingredient from direct light, and able to produce small particle size $\leq 24 \mathrm{~nm}$ (Ganesan and Narayanasamy, 2017; Mäder et al., 2001), hence it is able to protect the active substance from degradation and oxidation during the SLN manufacturing process (Katz et al., 2015; Pardeike et al., 2009).

The SLN preparation using a solvent emulsificationevaporation method was based on lipid precipitation in $\mathrm{o} / \mathrm{W}$ emulsion, the oil phase was dissolved in a water-immiscible organic solvent, then was dispersed into the aqueous phase with a surfactant to form o/w emulsion (Mehnert and Mader, 2012). In this study, SLNs were made using a combination of glyceryl monostearate (GMS) used at $1 \%$ and $2 \% \mathrm{w} / \mathrm{w}$ with a combination of EGCG concentrations of green tea extract equivalent to $1 \%$ and $2 \% \mathrm{w} / \mathrm{w}$. At the beginning of SLN manufacture, the green tea leaves extract was dissolved in $3 \mathrm{~mL}$ ethanol in order to solubilize EGCG in the oil phase, while lecithin and glyceryl monostearate were dissolved in an insoluble organic solvent of $10 \mathrm{~mL}$ dichloromethane. Subsequently, the EGCG solution was mixed using a homogenizer at a speed of 30,000 rpm for 15 minutes. In the SLN formulation, it is necessary to add a surfactant in order to stabilize and inhibit the agglomeration of dispersed fatty globules. The selected surfactant, 4\% poloxamer 188, was able to form an emulsion with a lower particle size and greater entrapment efficiency (Ekambaram and Abdul Hasan Sathali, 2011). Using a combination of surfactant (Phospholipon ${ }^{\circledR}$ 90G and Poloxamer 188 ) is able to improve stability during storage and able to create a smaller particle size (Mehnert and Mader, 2012).

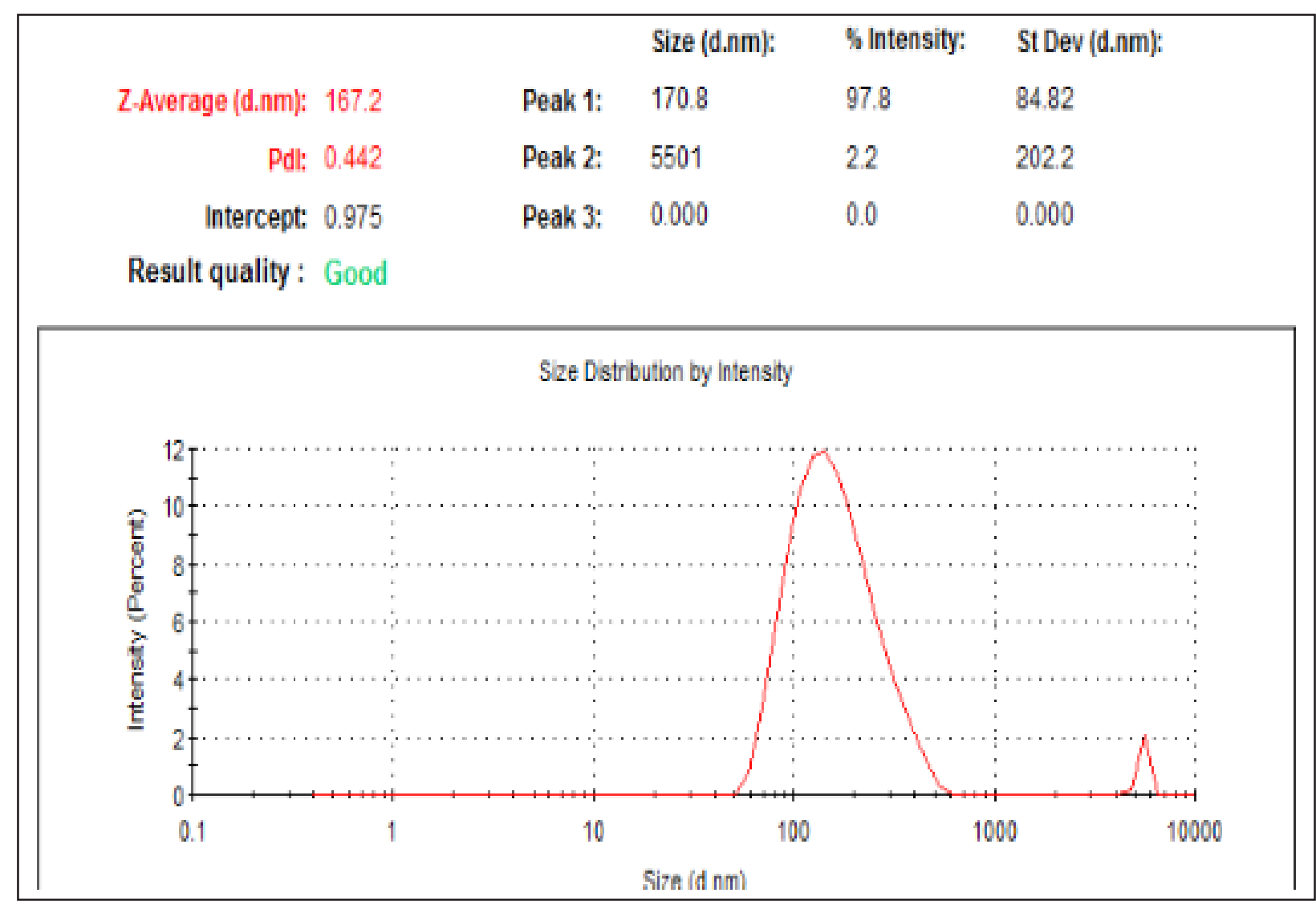

Fig. 1: Particle Size Distribution of GT-SLN1. 
Table 1: Formulation and Characterization of GT-SLN.

\begin{tabular}{|c|c|c|c|c|c|c|c|c|c|}
\hline Formulation & $\begin{array}{c}\text { EGCG (\%, } \\
\text { w/w) }\end{array}$ & GMS (\%, w/w) & $\begin{array}{l}\text { Lecithin }(\%, \\
\text { w/w) }\end{array}$ & $\begin{array}{c}\text { Poloxamer } 188 \\
(\%, w / w)\end{array}$ & Water (g) & Size (nm) & PDI & $\mathrm{ZP}(\mathrm{mV})$ & EE\% \\
\hline GT-SLN1 & 1 & 1 & 1 & 4 & qs 100 & $155.6 \pm 10.04$ & $0.409 \pm 0.05$ & $-30.967 \pm 1.29$ & $81.124 \pm 0.443$ \\
\hline GT-SLN2 & 1 & 2 & 1 & 4 & qs 100 & $178.4 \pm 1.11$ & $0.335 \pm 0.01$ & $-29.933 \pm 0.90$ & $82.385 \pm 0.407$ \\
\hline GT-SLN3 & 2 & 1 & 1 & 4 & qs 100 & $221.3 \pm 3.52$ & $0.438 \pm 0.02$ & $-30.067 \pm 1.18$ & $88.979 \pm 0.080$ \\
\hline GT-SLN4 & 2 & 2 & 1 & 4 & qs 100 & $280.2 \pm 7.34$ & $0.573 \pm 0.07$ & $-42.533 \pm 1.45$ & $89.136 \pm 0 . .222$ \\
\hline
\end{tabular}

Note: all values were represented as mean \pm S.D $(n=3)$.

Based on particle size and particle size distribution characterization from SLN formula, the result of GT-SLN1 had the smallest particle size that is $155.6 \pm 10.04 \mathrm{~nm}$ with a polydispersity index of $0.409 \pm 0.05$ (Fig. 1). The addition of $2 \%$ GMS on the GT-SLN2 formula was resulted in larger particle size than GT-SLN1 $(178.4 \pm 1.11 \mathrm{~nm})$. Based on the result of particle size, it can be seen that there is an effect of the GMS lipid addition on the SLN formula. Increasing amount of lipids can make greater particle size because it will increase the interface stress, therefore the lipid will agglomerate and produce a larger particle size. The result of polydispersity index analysis of SLN formula, obtained PDI value $\leq 0,5$ indicating that all SLN formulas had homogeneous particle size distribution. The smaller PDI value indicates the more homogeneous particle size distribution. The particle size and PDI measurements from SLN can be seen in Table 1.

Zeta potential measurement was made to predict the stability of SLN during storage. In general, particle aggregation tends to occur on charged particles. Positive or negative zeta potential values indicate the greater repulsive force of the charged particles, the less likely it is for the particles to aggregate. A good potential zeta value is above $+30 \mathrm{mV}$ or below $-30 \mathrm{mV}$ (Jose et al., 2014), while zeta potential $-15 \mathrm{mV}$ indicates the beginning of the gelation phenomenon (Mäder et al., 2001). The result of the zeta potential of SLN formula can be seen in Table 1. The result showed that all SLN formula had zeta potential below $-30 \mathrm{mV}$ which means it tends to be stable at the storage time and there is no gelation phenomenon.

\section{TEM analysis}

Fig. 2 shows the particle morphological form of the formula GT-SLN1. Particle morphology was analyzed using TEM imaging technique. Based on analysis of TEM showed that GT-SLN1 particle was a spherical shape.

\section{Entrapment efficiency (EE)}

The results of entrapment efficiency on all SLN formulas were ranged from $81.124 \pm 0.443 \%$ to $89.136 \pm 0.222 \%$. This research showed that increasing lipid concentration will increase entrapment efficiency since increasing lipid matrix will cause more space for the active substance to incorporate in the SLN. An increase in lipid levels may also reduce the release of the drug to an external phase, which may lead to increase entrapment efficiency (Jose et al., 2014) because of its low half-life $(<0.25 \mathrm{~h}$. Similarly, studies were done by Kelidari et al. (2015) and Akbari et al. (2016) proof that the greater composition of lipids will enhance the entrapment efficiency of the drug. The result of the entrapment efficiency can be seen in Table 1.

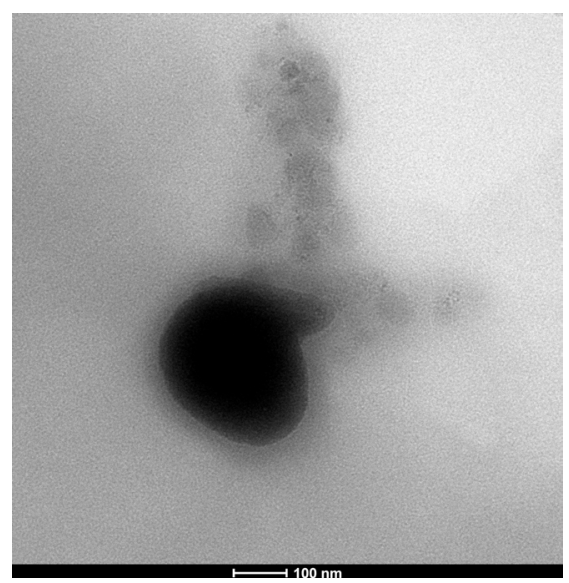

Fig. 2: TEM image of green tea leaves extract loaded SLN (GT-SLN1) with 97000 magnification.

\section{Differential scanning calorimetry (DSC) analysis}

The result of DSC analysis from GT powder showed that there were several peaks of a melting point such as $57.81^{\circ} \mathrm{C}$ with enthalpy value $-44.48 \mathrm{~J} / \mathrm{g}$ and $147.59^{\circ} \mathrm{C}$ with enthalpy value $-344.89 \mathrm{~J} / \mathrm{g}$ showing an endothermic reaction (see Fig. 3). For GMS powder, the results of DSC with peak melting point of $71.48^{\circ} \mathrm{C}$. In the physical mixture of GT-GMS, DSC results with peak melting point between $67.8^{\circ} \mathrm{C}$ and $103.19^{\circ} \mathrm{C}$. From this DSC result, there was no significant melting point between GMS with a physical mixture of GT-GMS. The results of the DSC GT-SLN analysis showed an endothermic reaction with a melting point of $58.29^{\circ} \mathrm{C}$ and an enthalpy value of $-98.00 \mathrm{~J} / \mathrm{g}$. These results were at the peak of the endothermic around the GMS melting point, but the peak of the endotherm of the GT was not visible. The possible cause is that solid lipids can inhibit crystallization of the active substance during nanoparticle formation. This is due to the active substances dissolved in the liquid lipid matrix resulting in the conversion of the active substance from the crystalline form to the amorphous form (Kelidari et al., 2015; Akbari et al., 2016). The thermogram formed at the measurement of the SLN melting point was appeared to be a sharp and narrow peak and the endothermic peak was in the vicinity of GMS solid lipid melting point.

\section{In vitro skin penetration study}

In this penetration study, the solvent used in the receptor compartment was phosphate buffer $\mathrm{pH} 5.5$ to maintain the stability of unstable EGCG compounds at an alkaline $\mathrm{pH}(\mathrm{pH}>$ 5.5) (Krupkova et al., 2016). The penetration test was analyzed for 12 hours at 12 point intervals. The result of penetration test 
conducted yields cumulative EGCG which penetrated for 12 hours from GT-SLN $13.006 \pm 0.152 \mu \mathrm{g} / \mathrm{cm}^{2}$ and GT 4,100 $\pm 0,054 \mu \mathrm{g} /$ $\mathrm{cm}^{2}$ (see Fig. 4). For the flux value by GT-SLN of $1.965 \pm 0.025$ $\mu \mathrm{g} / \mathrm{cm}^{2}$.hour and GT of $0.261 \pm 0.005 \mu \mathrm{g} / \mathrm{cm}^{2}$.hour. A comparison of EGCG flux values of GT-SLN with GT can be seen in Figure 5.

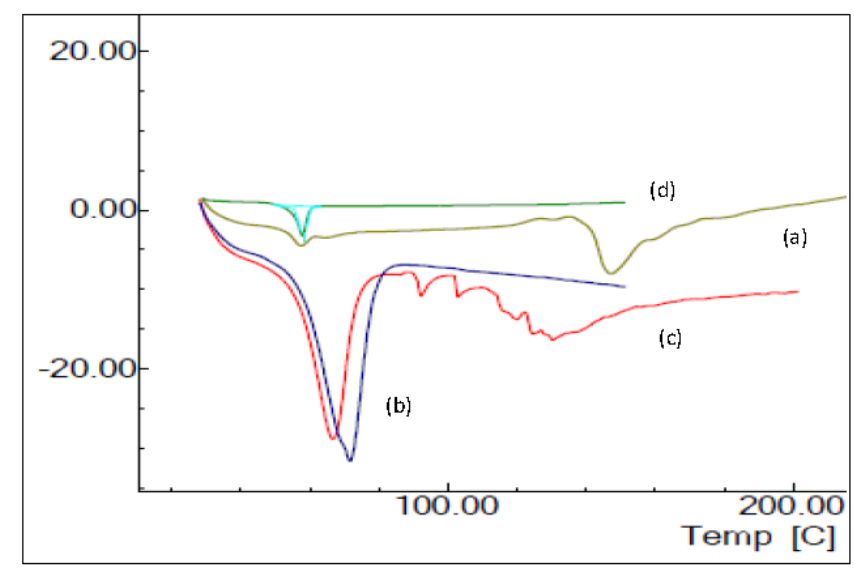

Fig. 3: DSC thermograms of (a) pure green tea leaves extract, (b) GMS, (c) physical mixture GT-GMS, and (c) GT-loaded SLN.

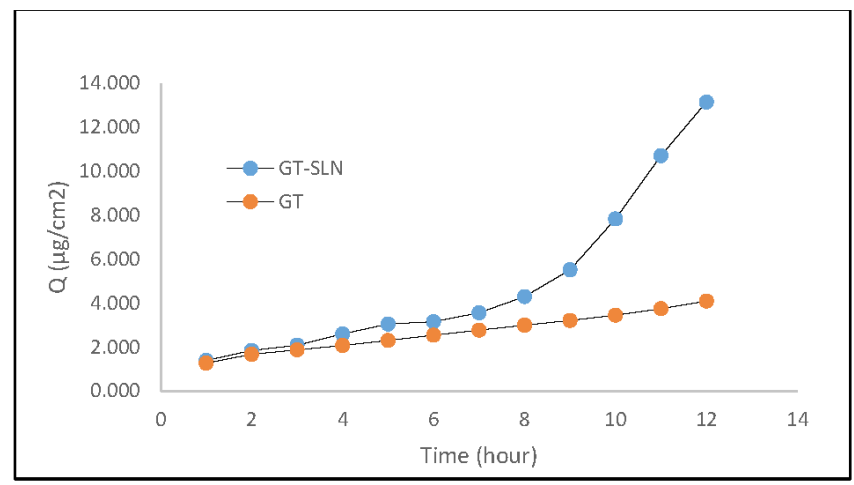

Fig. 4: Cumulative amount (Q) of GT-SLN and GT penetrated across rat skin $(\mathrm{n}=3)$.

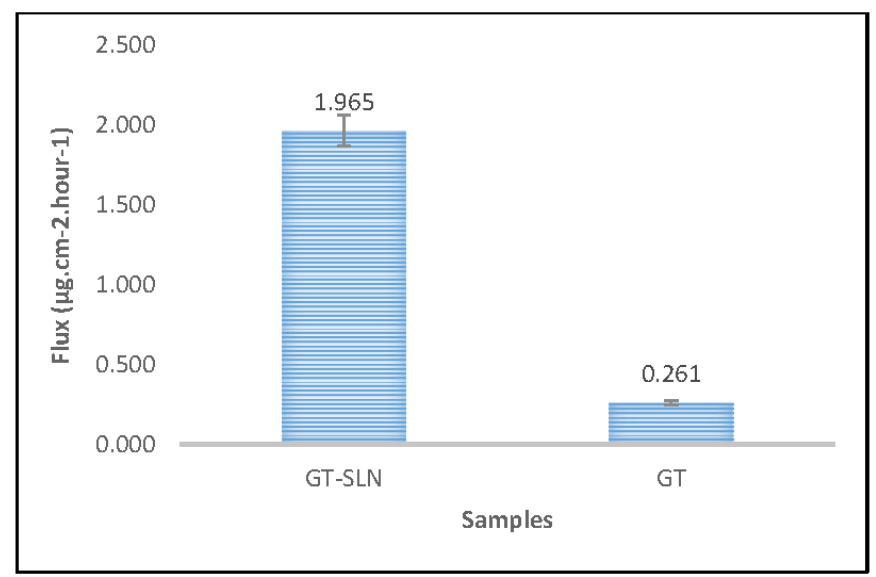

Fig. 5: Flux (J) of EGCG from GT-SLN and GT over $12 \mathrm{~h}$ using Franz Diffusion cells $(\mathrm{n}=3)$.
Table 2: Differential Scanning Calorimetry (DSC) Analysis.

\begin{tabular}{cccc}
\hline Samples & Onset $\left({ }^{\circ} \mathbf{C}\right)$ & Peak $\left({ }^{\circ} \mathbf{C}\right)$ & Enthalpy $(\mathbf{J} / \mathbf{g})$ \\
\hline GT & 141.6 & 147.59 & -344.89 \\
GMS & 59.09 & 71.48 & -2013.38 \\
Physical Mixture (GT-GMS) & 57.78 & 67.08 & -1414.94 \\
GT-SLN & 55.46 & 58.29 & -98.00 \\
\hline
\end{tabular}

These results indicate that GT-SLN preparations had a better penetration rate than those without SLN. The amount of cumulative drug penetrated the skin for 12 hours was very small because SLN persists on the applied skin surface due to the adhesive properties. SLN, when used on the surface of the skin, will form a film layer and form an adhesive layer that covers the skin. Moreover, there will be an increase in hydration of the stratum corneum which will increase the penetration of the drug into the skin layer. In addition, increased penetration is due to the occlusive effects of SLN. This occlusive effect is strongly influenced by particle size in which the properties of occlusive nanoparticles are 15 times more occlusive than microparticles. Where the occlusive properties are better at particle sizes less than $400 \mathrm{~nm}$ (Lv et al., 2009; Schafer-Korting et al., 2007). In this study, GT-SLN had a particle size of $155.6 \pm 10.04 \mathrm{~nm}(<400$ $\mathrm{nm}$ ), so the formed SLN had an occlusive effect that will lead to increase penetration into the skin layers.

\section{CONCLUSION}

Preparation of SLN using the solvent emulsificationevaporation method has been successfully developed for GT-SLN. The optimum formulations were GT-SLN1 with particle size 155.6 $\pm 10.04 \mathrm{~nm}$; polydispersity index $0.409 \pm 0.05$; zeta potential $-30.967 \pm 1.29 \mathrm{mV}$; entrapment efficiency $81.124 \pm 0.443 \%$ with spherical shape morphology. In vitro penetration study showed that EGCG formulated in SLN could increase EGCG penetration in the skin layer with higher EGCG flux in GT-SLN cream (1.965 $\pm 0.025 \mu \mathrm{g} / \mathrm{cm}^{2}$.hour $)$ than in GT cream $(0.261 \pm 0.005 \mu \mathrm{g} /$ $\mathrm{cm}^{2}$.hour). It can be concluded that SLN is able to increase the penetration of the drug into the skin and hence SLN can be used as an alternative carrier system for cosmetic preparations.

\section{ACKNOWLEDGMENT}

This research is financially supported by a research grant from National Agency of Drug and Food Control of Republic of Indonesia and Faculty of Pharmacy Universitas Indonesia.

\section{CONFLICT OF INTEREST}

The authors have declared no conflict of interest.

\section{REFERENCES}

Aafrin Thasleema S. Green tea as an antioxidant-A short review. J Pharm Sci Res, 2013; 5(9):171-173.

Akbari J, Saeedi M, Morteza-Semnani K, et al. The design of naproxen solid lipid nanoparticles to target skin layers. Colloids Surfaces B Biointerfaces, 2016; 145:626-633.

Balguri SP, Adelli GR, Majumdar S. Topical ophthalmic lipid nanoparticle formulations (SLN, NLC) of indomethacin for delivery to the posterior segment ocular tissues. Eur J Pharm Biopharm, 2016; 109:224235.

Ekambaram P, Abdul Hasan Sathali A. Formulation and 
evaluation of solid lipid nanoparticles of ramipril. J Young Pharm, 2011; 3(3):216-220.

Ganesan P, Narayanasamy D. Lipid nanoparticles: Different preparation techniques, characterization, hurdles, and strategies for the production of solid lipid nanoparticles and nanostructured lipid carriers for oral drug delivery. Sustain Chem Pharm, 2017; 6(May):37-56.

Jigisha A, Nishant R, Navin K, G. Pankaj. Green tea: A magical herb with miraculous outcomes. Int Res J Pharm, 2012; 3(5):139-148.

Jose S, Anju SS, Cinu TA, Aleykutty NA, Thomas S, Souto EB. In vivo pharmacokinetics and biodistribution of resveratrol-loaded solid lipid nanoparticles for brain delivery. Int J Pharm, 2014; 474(1-2):6-13.

Katz LM, Dewan K, Bronaugh RL. Nanotechnology in cosmetics. Food Chem Toxicol, 2015; 85:127-137.

Kelidari HRR, Saeedi M, Akbari J, et al. Formulation optimization and in vitro skin penetration of spironolactone loaded solid lipid nanoparticles. Colloids Surfaces B Biointerfaces, 2015; 128:473-479.

Krishnaveni M. Secrets of Epigallocatechin-3-Gallate (EGCG) in Green Tea. J Pharm Res, 2012; 5(12):5383-5389.

Krupkova O, Ferguson SJ, Wuertz-Kozak K. Stability of (-)-epigallocatechin gallate and its activity in liquid formulations and delivery systems. J Nutr Biochem, 2016; 37:1-12.

Lv Q, Yu A, Xi Y, et al. Development and evaluation of penciclovir-loaded solid lipid nanoparticles for topical delivery. Int $\mathrm{J}$ Pharm, 2009; 372(1-2):191-198.

Mäder K, Mehnert W, Mäder K. Solid lipid nanoparticles: Production, characterization and applications. Adv Drug Deliv Rev, 2001; 47(2-3):165-196

Mehnert W, Mader K. Solid lipid nanoparticles: Production, characterization and applications. Adv Drug Deliv Rev, 2012; 64(SUPPL.):83-101.

MüllerRH,RadtkeM, Wissing SA. Solid lipidnanoparticles(SLN) and nanostructured lipid carriers (NLC) in cosmetic and dermatological preparations. Adv Drug Deliv Rev, 2002; 54(SUPPL.):131-155.

Namal Senanayake SPJ. Green tea extract: Chemistry, antioxidant properties and food applications - A review. J Funct Foods, 2013; 5(4):1529-1541.

Pardeike J, Hommoss A, Müller RH. Lipid nanoparticles (SLN, NLC) in cosmetic and pharmaceutical dermal products. Int J Pharm, 2009; 366(1-2):170-184.

Patel AR, Velikov KP. Non-covalent interactions of green tea polyphenols: Source of novel colloidal structures. Handb Green Tea, 2013; 9:516-523.

Scalia S, Trotta V, Bianchi A. In vivo human skin penetration of (-)-epigallocatechin-3-gallate from topical formulations. Acta Pharm, 2014; 64(2):257-265

Schafer-Korting M, Mehnert W, Korting HC. Lipid nanoparticles for improved topical application of drugs for skin diseases. Adv Drug Deliv Rev, 2007; 59(6):427-443.

Gillbro JM, Olsson MJ. The melanogenesis and mechanisms of skin lightening agents - Existing and new approaches. Int J Cosmet Sci, 2011;33(3):210-221.

Sinija VR, Mishra HN. Green tea: Health benefits. J Nutr Environ Med, 2008; 17(4):232-242.

Sun Y, Hung WC, Chen FY, Lee CC, Huang HW. Interaction of tea catechin (-)-epigallocatechin gallate with lipid bilayers. Biophys J, 2009; 96(3):1026-1035.

Thakker KD, Chern WH. Development and validation of in vitro release tests for semisolid dosage forms-case study. Dissolution Technol, $2003 ; 10(2): 10-15$

\section{How to cite this article:}

Dzulhi S, Anwar E, Nurhayati T. Formulation, Characterization and in vitro Skin Penetration of Green tea (Camellia sinensis L.) Leaves Extract-Loaded Solid Lipid Nanoparticles. J App Pharm Sci, 2018; 8(08): 057-062. 